\title{
Effect of ageing on the calibration of ballistic gelatin
}

\author{
Jason Guey, ${ }_{1}^{1}$ S Rodrigues, ${ }^{1}$ A Pullen, ${ }^{1}$ B Shaw, ${ }^{1}$ D C Kieser ${ }^{2}$
}

'Defence Technology, Medical Corps, New Zealand Defence

Force, Auckland, Auckland, New Zealand

${ }^{2}$ Department of Orthopaedics, University of Otago, Dunedin, New Zealand

\section{Correspondence to}

D C Kieser, Department of Orthopaedics, University of Otago, Dunedin 9016, New Zealand; kieserdavid@gmail. com, kieserdavid@hotmail.com

Received 25 January 2018 Revised 8 February 2018 Accepted 8 February 2018 Published Online First 27 February 2018

Check for updates

To cite: Guey J, Rodrigues S,

Pullen A, et al.

J R Army Med Corps

2018:164:277-280

\section{ABSTRACT}

Purpose Ballistic gelatin is commonly used as a validated surrogate for soft tissue during terminal ballistic testing. However, the effect of a delay between production and testing of a gelatin mould remains unknown. The aim of this study was to determine any potential effects of ageing on ballistic gelatin.

Methods Depth of penetration (DoP) of $4.5 \mathrm{~mm}$ spherical fragment simulating projectiles was ascertained using mixtures of $10 \%, 11.25 \%$ and $20 \%$ Type A 250 Bloom ballistic gelatin. Testing was performed daily for 5 days using velocities between 75 and $210 \mathrm{~m} / \mathrm{s}$. DoP at day 5 was statistically compared with day 1 , and net mass change was recorded daily.

Results No significant difference was found for DoP observed with time in any of the samples $(P>0.05)$. Spearman correlation was excellent in all moulds. The moulds with known standard calibrations remained in calibration throughout the study period. Mass loss of less than $1 \%$ was noted in all samples.

Conclusion Mass loss was the only quantifiable measure of changes in the blocks with time, but did not correlate with any changes in DoP. This may provide reassurance when undertaking such testing that an inadvertent delay will not significantly alter the penetration properties of the mould. Future research is recommended to determine any potential effect on the mechanical properties of gelatin at higher velocity impacts and whether the calibration corresponds to an adequate simulation under such conditions.

\section{BACKGROUND}

Gelatin powder is an extract of animal material attained by soaking skin, bone and tendons in hot water and either an acid (type A) or a base (type B). ${ }^{1}$ It is typically combined with water to form a semisolid jelly mould. The grade of the mould is described as the Bloom number and is defined as the mass (g) of a $12.7 \mathrm{~mm}$ diameter stamp required to penetrate $4 \mathrm{~mm}$ into the surface of a gelatin mould without breaking it. Ballistic gelatin (Type A, 250 Bloom) is regularly used as a testing medium for terminal and wound ballistics because its mechanical properties simulate human skeletal muscle. ${ }^{1-5}$ However, multiple different brands of gelatin powder and concentrations of gelatin moulds have been trialled and are currently employed. ${ }^{36-10}$ This is because of the varying international opinions on which mixture is most representative of human soft tissue and therefore clinically applicable.

Multiple additional factors affect the mechanical properties of gelatin. A good example is temperature and hence why specific temperatures are advised for different concentrations. ${ }^{11} 12$ The two most common gelatin formulations currently used are $10 \%$ at $4^{\circ} \mathrm{C}$ (often termed 'Fackler gelatin') and $20 \%$ at $10^{\circ} \mathrm{C}$ ('NATO gelatin') based on the

\section{Key points}

- Under standard storage conditions, ballistic gelatin ageing, within 5 days, has no measurable effect on calibration testing.

- Under standard storage conditions, ballistic gelatin ageing within 5 days does not affect the expected linear relationship between penetration depth and projectile velocity.

- Researchers can be reassured that an inadvertent delay in testing will not markedly affect their results.

amount of powder per volume of the final gelatin mould. The timing of the testing is also important. ${ }^{11}$ Initially, the gelatin mould needs time to fully set or 'cure'. Testing in this interval may adversely affect results. Conversely, it has been presumed that the mechanical properties of gelatin may degrade with time and subsequently adversely affect the experimental findings. ${ }^{11}$ For this reason, it is widely believed that gelatin is best tested as soon as possible after curing.

Due to the multitude of variables involved, a calibration of the definitive gelatin has been suggested. Fackler and Malinowski performed tests on swine thighs, as a surrogate for human tissue, to determine the penetration depth of a $4.5 \mathrm{~mm}$ diameter steel ball fired at a velocity of $180 \pm 4.5 \mathrm{~m} / \mathrm{s}^{8}{ }^{8}$ Such a projectile has been used to simulate the effects of explosive injuries as a fragment simulating projectile. The authors found an average penetration depth of $85 \pm 10 \mathrm{~mm}$ at this velocity. Their results have been widely adopted as the current standard for $10 \%$ gelatin at $4^{\circ} \mathrm{C} .{ }^{11-14}$ Other authors have argued that swine thighs are poor surrogates for human soft tissue and hence alternative mixtures are used. However, to date, no published calibration standard, with comparison to penetration depth in a validated biological model, exists for alternative mixtures, including NATO gelatin. In addition, recent studies suggest that NATO gelatin fails to achieve the same penetration depths advocated by Fackler and Malinowski. ${ }^{8} 15$

While the ideal gelatin mixture is deliberately outside of the scope of this study, an understanding of the effect of ageing on the penetration depths of commonly used ballistic gelatin mixtures needs to be established. Particularly, because of the practical challenges involved in ballistic testing, which often result in unexpected delays between mould production and testing. Cronin and colleagues attempted to analyse the effect of such a delay on Fackler gelatin. ${ }^{11}$ While they concluded that a 72 hours delay did not affect the calibration results, their 
$10 \%$

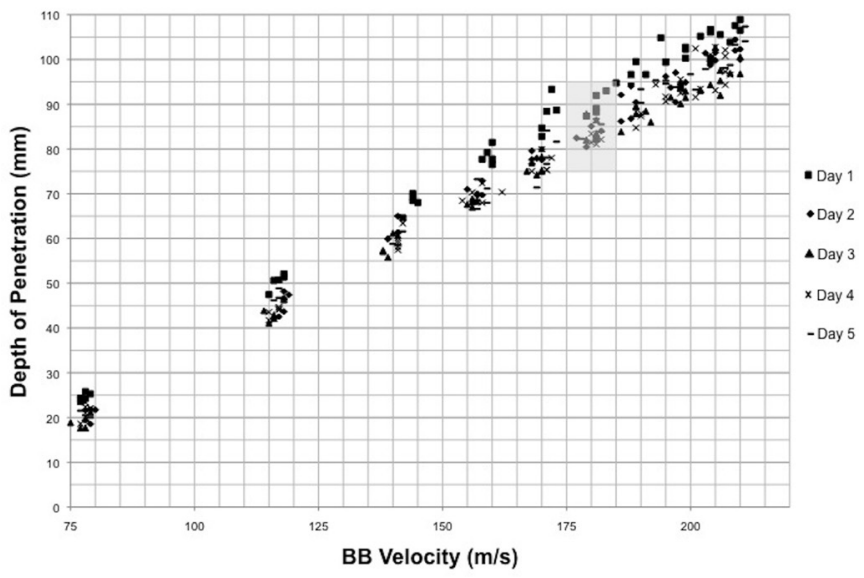

Figure 1 Penetration results of ball bearing (BB) into 10\% Vyse gelatin. Note the standard calibration zone shaded in grey.

study failed to ensure that their samples had fully cured prior to starting. Hence, their first 48 hours of testing found penetration depths outside of the calibration range. Furthermore, their study only assessed one type and mixture of gelatin. The aim of this study was to address the limitations in the literature and understand the effect of ageing, after curing, on the depth of penetration of a standardised calibration sphere in commonly used mixtures of ballistic gelatin.

\section{METHODS}

Three ballistic gelatin blocks (Type A 250 Bloom porcine gelatin by mass) of size $250 \times 250 \times 450 \mathrm{~mm}$ were produced in gel concentrations of 10\%, $11.25 \%$ and $20 \%$ (Vyse). With the exception of gel concentration, all three blocks were manufactured in an identical fashion. This involved adding the desired amount of gelatin to the appropriate amount of water vortexed at $50^{\circ} \mathrm{C}$ in a mixing drum. After completely dissolving the powder, the mixture was left to rest for $30 \mathrm{~min}$ to allow the majority of foam to clear. Excess foam was then scraped off the surface and the mixture was poured into the moulds. These were then left overnight at room temperature $\left(20^{\circ} \mathrm{C}\right)$ and the next day placed into the chillers to fully cure.

$11.25 \%$

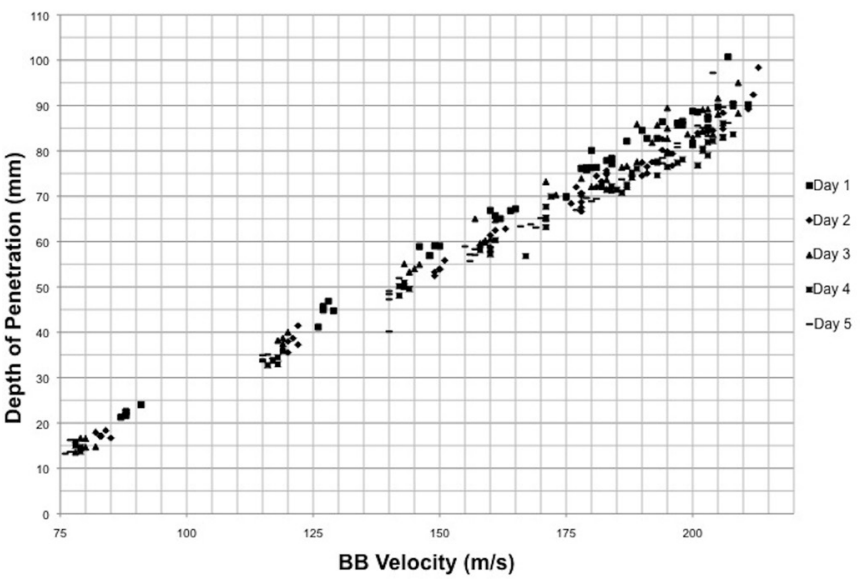

Figure 2 Penetration results of ball bearing (BB) $11.25 \%$ Vyse gelatin.
An additional trial using the same mould size and production method was performed with a 10\% mixture Type A 250 Bloom ballistic gelatin from a different manufacturer (Gelita $\mathrm{NZ)} \mathrm{to} \mathrm{confirm} \mathrm{calibration} \mathrm{maintenance.} \mathrm{All} \mathrm{blocks} \mathrm{were} \mathrm{stored}$ according to their published standard: Fackler gelatin and $11.25 \%$ gelatin in a Skope SK1000-2 fridge at $4^{\circ} \mathrm{C}$ and NATO gelatin in a Vötsch 1500 environmental test chamber at $10^{\circ} \mathrm{C}$. All gel blocks were wrapped in plastic to minimise water loss through evaporation.

After curing, calibration was confirmed with penetration depth testing. Penetration depth tests were performed with standardised steel ball bearings $(0.3 \mathrm{~g}, 4.5 \mathrm{~mm})$, as per Fackler and Malinowski, fired out of a Daisy PowerLine 901 multipump air rifle $2.2 \mathrm{~m}$ from the surface of the block. ${ }^{8}$ The preimpact velocities were recorded using Oehler 57 velocity screens with screens spaced $2 \mathrm{~m}$ apart. The velocity range tested was $75-210 \mathrm{~m} / \mathrm{s}$. Five shots were fired into the long side of each block every day for 5 days at each pump interval of the air rifle and the depth of penetration measured for each shot. The Gelita mould was tested over an entire week. Temperature was monitored with a probe thermometer inserted into the block during shooting. In order to maintain consistency, blocks were returned to the chillers after $30 \mathrm{~min}$ at room temperature or if the temperature reading had increased by more than $0.5^{\circ} \mathrm{C}$ over the course of the testing.

Calibration tests were compared with the published calibration coefficients for the $10 \%$ mixtures. ${ }^{8}$ Comparison to published calibration coefficients was not performed for $11.25 \%$ or $20 \%$ gelatin, as no published calibration coefficients are available for these gelatin concentrations using $4.5 \mathrm{~mm}$ ball bearings. In addition, the gelatin blocks were penetration tested over the full range of achievable velocities to establish a trend between penetration depth and projectile velocity. The (net) mass of the blocks were recorded after curing and at the end of testing for all Vyse gelatin moulds. Comparison of the day 5 and day 1 penetration depths was performed with a $\square^{2}$ test. In addition, a Spearman correlation coefficient of day 5 was compared with day 1. Statistical significance was defined as a $P$ value $<0.05$ and a Spearman's correlation coefficient greater than 0.9 described as an excellent correlation.

\section{RESULTS}

Figures 1-4 show the depth of penetration of ball bearings as a function of projectile velocity $(\mathrm{m} / \mathrm{s})$ and time (days). The grey



Figure 3 Penetration results of ball bearing (BB) into 20\% Vyse gelatin. 


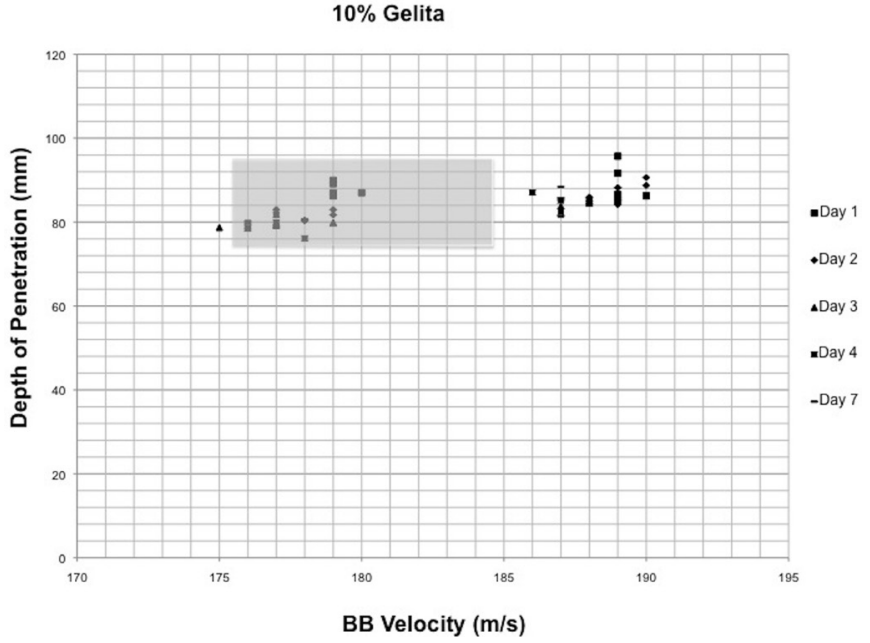

Figure 4 Penetration results of ball bearing (BB) into 10\% Gelita over 7 days. Note the standard calibration zone shaded in grey.

boxes overlaid on graphs 1 and 4 illustrate the reported standard calibration, and thus, the region in which the depth of penetration must lie in order for the block to pass calibration testing. ${ }^{8}$ No significant change in the penetration depth was noted in any of the gelatin samples over the study period $(\mathrm{P}>0.05$ in all samples). All Spearman correlation coefficients exceeded 0.9. The 10\% Vyse gel remained in calibration for the entire duration and ageing appeared to have no effect (outside of the normal gel variation) on penetration depth for a given velocity $(\mathrm{P}=0.532)$ (Figure 1).

The $11.25 \%$ gel showed as similar linear trend line to that of the other gelatin blocks (Figure 2). No significant variance was found with time over the course of this study $(\mathrm{P}=0.850)$.

The 20\% gelatin also showed no variation with time $(\mathrm{P}=0.827)$ (Figure 3$)$. In addition, there was no skin hardening effect, with a minimum penetration velocity of $88 \mathrm{~m} / \mathrm{s}$ for all samples. Overall, its penetration depth was significantly lower than the $10 \%$ gelatin $(\mathrm{P}=0.000)$.

Net mass of all Vyse gelatin moulds decreased with time. The $20 \%$ gelatin mould stored in the environmental test chamber lost $260 \mathrm{~g}(0.9 \%$ of total mass of gelatin block) over 6 days, whereas the $10 \%$ and $11.25 \%$ concentrations both lost $40 \mathrm{~g}(0.1 \%)$ over the same time period. The $10 \%$ Gelita gelatin maintained its calibration over 7 days with no significant change in penetration depth noted $(\mathrm{P}=0.974)$ (Figure 4).

\section{DISCUSSION}

Ballistic gelatin is routinely used worldwide to simulate animal and human muscle penetration in the field of wound ballistics. However, there are multiple factors which can affect the performance of this medium. ${ }^{11} 16$ One factor previously thought to affect its performance was ageing. ${ }^{11}$ This study has found that ageing, within 5 days, has no appreciable effect on the depth of penetration, of a standardised calibration sphere, in commonly used ballistic gelatin mixtures. Furthermore, it has shown that, within the velocity range tested, ageing does not affect the linear relationship expected for the depth of penetration according to impact velocity. 51617

Mass loss was the only quantifiable measure of changes in the blocks with time. We believe this mass loss relates to mould dehydration from evaporation and that the difference between blocks is attributed to the humidity difference between the environmental test chamber and the fridge. However, the decrease in mass of the blocks did not correlate with any changes in penetration behaviour. Therefore, the magnitude of water loss (less than $1 \%$ ) is considered insignificant to affect block penetration results.

Importantly, 20\% gelatin develops a hardened 'skin' on its surface with curing, and there is concern that this skin may harden with time, or dehydration, to increase the penetration threshold. ${ }^{11}$ Breeze and colleagues found no such effect when testing recently cured gelatin blocks; however, no previous studies have addressed the effect of time on skin hardening and penetration threshold. ${ }^{11}$ In this study, we found no observable change in the velocity threshold required for penetration with time. However, it is acknowledged that the sample size for threshold velocities was insufficient to statistically analyse, and therefore we would advocate further research into this area. Reassuringly though, the depth of penetration at higher velocities was not significantly different with time, and therefore we believe that any change in skin hardening is likely to be insignificant.

It should also be recognised that alternative projectile sizes and velocities have been proposed for the calibration of various mixtures of gelatin. Breeze et al suggested a $5.0 \mathrm{~mm}$ ball bearing, whereas Mabbott et al suggested a $5.5 \mathrm{~mm}$ ball bearing as these are felt to be more representative of a typical sized fragment and round, respectively. ${ }^{18-22}$ However, the larger and faster a calibration sphere, the more likely it is to affect the gelatin blocks mechanical behaviour during definitive testing. We therefore maintained a $4.5 \mathrm{~mm}$ ball bearing for all mixtures.

The results of this study reassure those involved in such testing that an inadvertent delay will not significantly alter the penetration properties of the mould. However, this study is limited by only assessing penetration depth as a measure of gelatin performance. To date, this is the standard technique utilised to ensure adequate gelatin properties for ballistic testing. However, it fails to determine the effect of the gelatin's mechanical properties at higher velocity impacts and whether the calibration accurately depicts the effects of high-velocity projectiles. ${ }^{23}$ Further research into this area, including temporary and permanent cavity size, depth and nature, should be performed.

\section{CONCLUSIONS}

Under standard storage conditions, ballistic gelatin ageing, within 5 days, has no measurable effect on calibration testing. Furthermore, it does not affect the expected linear relationship between penetration depth and projectile velocity. Researchers can therefore be reassured that an inadvertent delay in testing will not markedly affect their results.

Contributors All authors contributed equally to this project.

Funding This research received no specific grant from any funding agency in the public, commercial or not-for-profit sectors.

Competing interests None declared.

Patient consent Not required.

Provenance and peer review Not commissioned; externally peer reviewed.

(C) Article author(s) (or their employer(s) unless otherwise stated in the text of the article) 2018. All rights reserved. No commercial use is permitted unless otherwise expressly granted.

\section{REFERENCES}

1 Sellier KG, Kneubuehl BP. Wound ballistics and the scientific background. Elsevier, 1994.

2 Harvey EN, Butler JH, McMillan EG, et al. Mechanism of wounding. In: Coates JB, Beyer JC, Wound ballistics. Washington DC: Office of the Surgeon General, Department of the Army, 1962. 
3 Lewis RH, Clark MA, O?Connell KJ. Preparation of gelatin blocks containing tissue samples for use in ballistics research. Am J Forens Med Path 1982;3:181-4.

4 Fackler ML, Malinowski JA. Ordnance gelatin for ballistic studies. Detrimental effect of excess heat used in gelatin preparation. Am J Forensic Med Pathol 1988;9:218-9.

5 Jussila J. Preparing ballistic gelatine - review and proposal for a standard method. Forens Sci Int 2004:141:91-8.

6 DeMuth WE. Bullet velocity and design as determinants of wounding capability: an experimental study. J Trauma 1966:6:222-32

7 Berlin R, Janzon B, Rybeck B, et al. Local effects of assault rifle bullets in live tissues. Part II. Further studies in live tissues and relations to some simulant media. Acta Chir Scand 1977:477:1-48.

8 Fackler ML, Malinowski JA. The wound profile: a visual method for quantifying gunshot wound components. J Trauma 1985;25:522-9.

9 Peters CE. A mathematical-physical model of wound ballistics. J Trauma 1990;6:303-18.

10 Janzon B, Hull JB, Ryan JM, et al. Projectile-material interactions: soft tissue and bone. In: Cooper GJ, Dudley HAF, Gann DS, Scientific foundations of trauma. Oxford: Butterworth, Heinemann, 1997.

11 Cronin DS, Falzon C. Characterization of $10 \%$ ballistic gelatin to evaluate temperature, aging and strain rate effects. Exp Mech 2011:51:1197-206.

12 Fackler ML, Kneubuehl BP. Applied wound ballistics, what's new and what's true. J Trauma 1990:6:32-7.

13 Fackler ML. Wound profiles. Wound Ballist Rev 2001;5:25-38.

14 MacPherson D. Tissue Simulation. Bullet penetration: modeling the dynamics and the incapacitation resulting from wound trauma. California: Ballistics Publications, 1994:67-86.
15 Maiden NR, Fisk W, Wachsberger C, et al. Ballistics ordnance gelatine - how different concentrations, temperatures and curing times affect calibration results. J Forensic Leg Med 2015;34:145-50.

16 Swain MV, Kieser DC, Shah S, et al. Projectile penetration into ballistic gelatin. J Mech Behav Biomed Mater 2014;29:385-92.

17 Akers B, Belmonte A. Impact dynamics of solid spheres into a visco-elastic micellar fluid. J Non-Newtonian Fluid Mech 2006;138:97-108.

18 Mabbott A, Carr DJ, Champion S, et al; Comparison of 10\% Gelatin, 20\% Gelatin and Permagel For Ballistic Testing. 27th International Symposium on. . Ballistics, Freiburg, Germany, 2013:654. 648.

19 Breeze J, Carr DJ, Mabbott A, et al. Refrigeration and freezing of porcine tissue does not affect the retardation of fragment simulating projectiles. J Forensic Leg Med 2015:32:77-83.

20 Breeze J, James GR, Hepper AE. Perforation of fragment simulating projectiles into goat skin and muscle. J R Army Med Corps 2013;159:84-9.

21 Breeze J, Sedman AJ, James GR, et al. Determining the wounding effects of ballistic projectiles to inform future injury models: a systematic review. J R Army Med Corps 2014; 160:273-8

22 Breeze J, Hunt N, Gibb I, et al. Experimental penetration of fragment simulating projectiles into porcine tissues compared with simulants. J Forensic Leg Med 2013;20:296-9.

23 Shepherd CJ, Appleby-Thomas GJ, Hazell PJ, et al; The dynamic behaviour of ballistic gelatine. Proceedings of the American Physical Society Topical Group on shock compression of condensed matter. Nashville USA: American Institute of Physics, 2009:1399-402. 